\title{
HIV-Associated Lymphoproliferative Disorder
}

National Cancer Institute

\section{Source}

National Cancer Institute. HIV-Associated Lymphoproliferative Disorder. NCI Thesaurus.

Code C157709.

A lymphoproliferative disorder that develops in an individual with HIV infection. 